Enfermagem Brasil 2016;15(4):198-205

\title{
ARTIGO ORIGINAL \\ Presença do pai no momento do parto: percepções e sentimentos das puérperas
}

\begin{abstract}
Aldaíza Ferreira Antunes Fortes, M.Sc. ${ }^{\star}$, Tatiana Von Pinho Costa**
*Enfermeira, Escola de Enfermagem da Universidade Federal de Minas Gerais (UFMG), Docente das disciplinas Estágio Supervisionado II, Estágio Supervisionado IV, Relato de Práticas Clínicas em Enfermagem e Relato de Práticas Gerenciais em Enfermagem do Curso de Graduação em Enfermagem, da Escola de Enfermagem Wenceslau Braz (EEWB), Membro do Núcleo de Estudo e Pesquisa em Enfermagem e Coordenadora do Comitê de Ética em Pesquisa da EEWB, Minas Gerais, ${ }^{* *}$ Enfermeira, Graduada em Enfermagem, pela Universidade do Estado de Minas Gerais (UEMG), Enfermeira Auditora da Unimed Lavras Cooperativa de Trabalho Médico, Lavras/MG

Texto construído a partir da Monografia, do Curso de Pós-graduação "Latu Sensu" em Enfermagem Obstétrica e Neonatologia, Escola de Enfermagem Wenceslau Braz (EEWB), Itajubá/MG.
\end{abstract}

Recebido em 22 de junho de 2015; aceito em 25 de fevereiro de 2016.

Endereço para correspondência: Aldaíza Ferreira Antunes Fortes, Rua Zequinha Luiz, 29, Bairro Varginha 37501-074 Itajubá MG, E-mail: aldaizafortes1@hotmail.com.br, tatianavpcosta@yahoo.com.br

\section{Resumo}

Objetivos: Conhecer as percepções e os sentimentos das puérperas acerca da presença do pai no momento do parto. Métodos: Estudo qualitativo, do tipo exploratório, descritivo. A amostragem foi do tipo proposital. Após aprovação do Comitê de Ética em Pesquisa da Escola de Enfermagem Wenceslau Braz, de Itajubá/MG colheram-se os dados por meio de dois instrumentos: um estruturado contendo informações relacionadas às características pessoais das participantes do estudo e um roteiro de entrevista aberta composto por duas questões. Tais dados foram analisados e interpretados utilizando a estatística descritiva e a análise de conteúdo, respectivamente, para cada instrumento. Resultados: Para as 10 puérperas entrevistadas a presença do pai no momento do parto significa "segurança, força, união e interesse"; "foi muito importante" e, "calma e tranquilidade". Ao terem o pai presente no momento do parto elas se sentem "bem, bastante emocionadas e muito felizes"; "mais confiantes e seguras", "estar vivendo e dividindo um momento só nosso" e, "mais tranquilas". Conclusão: As puérperas são extremamente beneficiadas com a presença do pai no momento do parto.

Palavras-chave: pai, parto humanizado, percepção, assistência de enfermagem.

\begin{abstract}
Father's presence at birth: perceptions and feelings of mothers

Objectives: To know the perceptions and the feelings of mothers concerning father's presence at childbirth. Methods: This is a qualitative, exploratory and descriptive study. The sampling was purposeful type. After approved by the Ethics and Research Committee of School of Nursing Wenceslau Braz, of Itajubá/MG data was collected using two instruments: one structured containing information related to personal characteristics of the participants of the study and a composed script of open interview for two questions. Data were analyzed and interpreted using the descriptive statistics and the analysis of content, respectively, for each instrument. Results: The ten puerperal interviewed reported that father's presence at childbirth means "security, strength, union and interest"; "it was very important; and "calm and peace of mind". The father's presence at childbirth helps the women feel "well, deeply moved and very happy"; "more confident and secure", "experiencing and sharing a moment just for us" and, "more peaceful". Conclusion: The women are extremely benefited from their husband's presence at childbirth.
\end{abstract}

Key-words: father, humanized delivery, perception, nursing care. 


\section{Resumen \\ La presencia del padre en el momento del parto: percepciones y sentimientos de las madres}

Objetivos: Conocer las percepciones y sentimientos de puérperas acerca de la presencia del padre en el momento del parto. Métodos: Se trata de estudio cualitativo, exploratorio, tipo descriptivo. El muestreo ha sido del tipo intencionado. Después de laaprobación del Comité de Ética en Investigación de la Escuela de Enfermería Wenceslau Braz, Itajubá/MG, los datos fueron recolectados por medio de dos instrumentos: uno estructurado conteniendo información relacionada con las características personales de los participantes del estudio y de un guion de entrevista compuesto por dos preguntas. Los datos fueron analizados e interpretados usando la estadística descriptiva y el análisis de contenido, respectivamente, para cada instrumento. Resultados: Para las 10 puérperas la presencia del padre en el momento del parto significa "seguridad, fuerza, unión e interés"; "muy importante" y "calma y tranquilidad". Al tener la presenciad del padre en el momento del parto se sienten "bien, muy emocionadas y muy felices"; "más confiadas y seguras", "viviendo y compartiendo un momento solamente nuestro" y "más tranquilas". Conclusión: Las puérperas se benefician extremadamente con la presencia del padre en el momento del parto.

Palabra-clave: padre, parto humanizado, percepción, atención de enfermería.

Introdução

Os hospitais são referências no atendimento à saúde e, na maioria das vezes, são equipados com recursos humanos especializados; recursos físicos e financeiros para um atendimento de qualidade às gestantes. Entretanto o que parece ser adequado para esses requisitos nem sempre é humanizado ao paciente.

O Ministério da Saúde (MS) criou, em 2001, o Programa de Humanização no Pré-Natal e Nascimento (PHPN) com o objetivo de disseminar conceitos e práticas da assistência ao parto entre os profissionais de saúde; incorporando a capacitação técnica à necessidade de humanizar o processo de atenção à mulher durante a gestação e o parto.

Foi necessário criar uma lei específica para que houvesse mudanças no modelo assistencial dominante e garantisse uma medida que humanizasse o parto hospitalar, permitindo a gestante o direito de um acompanhante durante todo o trabalho de parto e pósparto imediato.

A Lei Federal $n^{0}$ 11.108, de 7 de abril de 2005, sancionada pelo presidente em exercício José Alencar, garante às gestantes o direito à presença de um acompanhante durante o trabalho de parto, parto e pós-parto imediato, no âmbito do Sistema Único de Saúde (SUS), de redes próprias ou conveniadas [1].

Para as parturientes entrar em um local desconhecido, frio, branco, silencioso, com odores distintos, encontrar pessoas diversas e deixar serem tocadas ou serem submetidas a algum procedimento médico é, na maioria das vezes, assustador e até mesmo traumático. Por mais que um Hospital seja bem estruturado, as gestantes não estão familiarizadas com esse ambiente e muito menos com as pessoas que ali trabalham, tornando o momento do parto muitas vezes complicado; pela ansiedade, insegurança e medo.

O médico obstetra de renome Dr. Grantly Dick Read publicou, em 1933, em seu livro, a teoria que a dor durante o trabalho de parto é causada pelo medo. Sendo assim, as mulheres que são orientadas e preparadas para o trabalho de parto natural conseguem controlar o medo, a tensão e a dor [2].

O acompanhante escolhido pela gestante é uma pessoa familiar, na qual ela confia. Por isso, passar a experiência do parto com o esposo ao lado, e este participando efetivamente, acalmando-a, confortando-a e ajudando-a a suportar o medo, a tensão e a dor é muito significativo para a parturiente.

Para que o esposo possa ajudar a mulher, durante o trabalho de parto, é importante auxiliá-lo a tomar conhecimento da impressão que poderá ter ao ver alguém que ama sentindo dores e como reagirá às diversas observações, sons e odores do hospital e da sala de parto. A orientação ao pai é fundamental para enfrentar com maior eficácia o momento do parto, tornando-se participativo e não apenas mero observador [2].

Entretanto, mesmo criando programas, lei e ações para humanizar o parto; percebe-se o despreparo de hospitais e a insatisfação de profissionais de saúde ao lidar com a presença 
de acompanhante; o qual observa e pode opinar nas ações intervencionistas que a gestante será submetida.

Humanizar a assistência ao parto e nascimento é um desafio para as instituições e profissionais de saúde, pois implica em mudanças de atitudes e rotinas, tornando esse momento o menos medicalizado possível, utilizando-se de práticas assistenciais que garantam a integridade física e psíquica dos seres envolvidos nesse processo [3].

Dodou et al. [4:268] ressaltam que "é importante não só incentivar a presença de um acompanhante para todas as mulheres, mas também que esses sejam preparados e orientados para ajudar a mulher durante o parto e nascimento, assumindo uma participação ativa nesse período que envolve tantas emoções".

Mediante este contexto e as dificuldades da equipe de saúde em lidar com a presença do acompanhante na sala de parto e salas operatórias, surgiu à inquietude em conhecer as percepções e os sentimentos das puérperas em relação à presença do esposo no momento do parto.

Diante deste panorama, este estudo teve como objetivos: conhecer as percepções e os sentimentos das puérperas acerca da presença do pai no momento do parto.

Material e métodos

Trata-se de uma pesquisa de abordagem qualitativa, do tipo exploratório, descritivo e transversal, realizada com 10 puérperas assistidas na Maternidade Delma Eli Brunhara do Hospital Vaz Monteiro de Assistência Materno-Infantil, da cidade de Lavras/MG e que tiveram o pai da criança acompanhando-as no momento do parto.

É importante destacar que estas puérperas podiam ser de parto vaginal ou cesáreo.

Os critérios de inclusão das participantes da pesquisa foram: ser puérpera, no mínimo secundípara, de parto vaginal ou cesáreo que teve o pai acompanhando-a no momento do parto na Maternidade Delma Eli Brunhara do Hospital Vaz Monteiro de Assistência MaternoInfantil, da cidade de Lavras/mg; ser maior de 18 anos e concordar em participar do estudo. Enquanto os critérios de exclusão foram: ser puérpera, no mínimo secundípara ou não, de parto vaginal ou cesáreo que não teve o pai acompanhando-a no momento do parto na referida Maternidade; ser puérpera primípara de parto vaginal ou cesáreo que teve o esposo acompanhando-a no momento do parto na Maternidade em questão; ser menor de 18 anos e não concordar em participar da pesquisa.

Optou-se pelas puérperas, no mínimo secundíparas, por achar que certamente a percepção e sentimentos das primíparas são diferentes em relação às demais puérperas.

A coleta de dados só foi iniciada após a autorização da Gestora Administrativa do Hospital supracitado, e, a aprovação do projeto desta pesquisa, pelo Comitê de Ética em Pesquisa, da Escola de Enfermagem Wenceslau Braz, da cidade de Itajubá/MG, conforme parecer consubstanciado $\mathrm{n}^{\circ}$ 331.840/2013. Ocorreu por meio de dois instrumentos: o primeiro referente à caracterização pessoal das participantes do estudo como idade, religião, escolaridade, profissão, estado civil, número de filhos, participação anterior do pai no momento do parto e quem quis a presença do pai no momento do parto; já o segundo abordou duas questões abertas inerentes aos objetivos do estudo: "O que significou, para você, a presença do pai no momento do parto?" e "Como você se sentiu ao ter o pai presente no momento do parto?".

Antes da utilização definitiva destes instrumentos, foi realizado um pré-teste com três puérperas, que satisfizeram os critérios de inclusão expostos anteriormente. Elas fizeram parte da amostra, pois não houve a necessidade de ajuste ou modificação nos instrumentos utilizados para a coleta de dados. O pré-teste serviu para indicar três importantes elementos: fidedignidade, validade e operatividade [5].

As entrevistas ocorreram no período de agosto a outubro de 2013 e foram registradas em gravador de voz em MP4 com 2G de memória e a seguir transcritas conforme os critérios metodológicos, permitindo a fidedignidade das informações colhidas. Após a transcrição das falas do registro gravado, foram transferidas e arquivadas em um pendrive, onde permanecerão arquivadas por um período de cinco anos após o término da pesquisa. Em seguida, serão deletadas.

O tempo gasto para cada entrevista foi em torno de 15 minutos. É importante ressaltar que as puérperas foram entrevistadas pelo menos oito horas após o parto para que pudessem descansar e recuperar, haja vista que o desgaste emocional ocorrido durante o mesmo poderia interferir na natureza dos dados coletados. 
Para análise dos dados relacionados à caracterização pessoal das participantes foi utilizada a estatística descritiva, por meio das frequências, absoluta e relativa. Enquanto que os referentes às duas questões abertas foram analisados e interpretados por meio da análise de conteúdo, que, é um procedimento bastante utilizado nas abordagens qualitativas [6].

A análise de conteúdo consiste em uma técnica para investigar o conteúdo das comunicações humanas, isto é, visa os produtos das ações humanas, voltando-se para o estudo das ideias e não das palavras em si. É caracterizada pela busca do atendimento da comunicação entre os homens baseando-se no reconhecimento do conteúdo das mensagens [5]. Pode ser sintetizada em cinco passos, a saber: apreensão da globalidade dos relatos; obtenção de uma visão global dos relatos e do local onde se encontram os significados; agrupamento das unidades de significados semelhantes; agrupamento dos temas, extraídos das unidades de significados, originando as categorias e análise das categorias emergidas [6].

O presente estudo seguiu os preceitos estabelecidos pela Resolução 196/96 versão 2012, do Conselho Nacional de Saúde. O anonimato de cada participante foi preservado utilizando a codificação $\mathrm{P} 1, \mathrm{P} 2, \mathrm{P} 3$, proveniente da palavra puérpera e do número ordinal sequencial de acordo com o número de entrevistadas, totalizando dez puérperas.

\section{Resultados e discussão}

No tocante às características pessoais das entrevistadas, observou-se que a faixa etária oscilou entre 20 e 43 anos, predominando as idades entre 31 e 40 anos, correspondendo a $80 \%$ da amostra. Prevaleceu a religião católica com $50 \%$; o terceiro grau completo como nível de escolaridade com $50 \%$; odontóloga como profissão com $20 \%$; casada como estado conjugal com $100 \%$; dois filhos como número de filhos com $90 \%$; ambos, pai e puérperas, quiseram a presença do pai no momento do parto com $70 \%$; não ter a presença anterior do pai no momento do parto, com $60 \%$; e dos $40 \%$ que teve a presença anterior do pai no momento do parto, $20 \%$ informaram que isso ocorreu uma vez e $20 \%$ mencionou duas vezes.

Ao analisar as respostas das entrevistadas inerentes à primeira questão aberta: "O que significou, para você, a presença do pai no momento do parto?", evidenciaram-se três categorias: "segurança, força, união e interesse"; "foi muito importante" e "calma e tranquilidade".

\section{1aㅡ Categoria: Segurança, força, união e interesse}

Analisando esta categoria, percebe-se que, para as 10 entrevistadas, terem o pai presente no momento do parto significou segurança, força, união e interesse para elas, como expresso nos depoimentos:

"Segurança. É ficar acompanhada, se precisar de alguma coisa, tá ali alguém da família presente." (P1).

"[...] ele me dá mais segurança, tendo ele do meu lado. Eu me senti mais segura." (P2).

"Eu me senti mais segura com ele." (P3).

"Ele acompanhou a gravidez inteira, em todos os momentos ele estava lá presente. É uma força que dá pra gente, segurança."(P4).

"[...] traz segurança, não fiquei ali sozinha e ai tem alguém para acompanhar o neném, então é segurança mesmo." (P5).

"Mais segurança, porque eu tive medo, ai uma pessoa que eu gosto, que eu conheço, estava ali para ficar me dando força." (P6).

"Bom, muito bom, segurança, isso é bom." (P7).

"Segurança, união, interesse, foi isso." (P8).

"Segurança por ele estar ali comigo. Ele ver que está tudo bem." (P9). 
"[...] me senti mais segura, ter ele ali do meu lado." (P10).

Ter a presença do pai no momento do parto propícia a puérpera vários significados, um deles é a segurança, que foi mencionada por todas as entrevistadas. A puérpera cria expectativa em relação ao trabalho de parto e parto, sente medo do desconhecido, e ter alguém conhecido, principalmente o pai de seu bebê, acompanhando-a faz com que ela sinta mais força, segurança e a certeza de que se precisar de alguma ajuda será atendida. Ademais estabelece uma união da tríade ao fortalecer o vínculo entre pai, mãe e filho.

A presença do pai durante o trabalho de parto de sua companheira é fonte de apoio, segurança, conforto e fortalecimento de vínculos afetivos. A responsabilidade perdura mesmo após o parto, incluindo-o no aconchego da família como ser que sofre, chora, emociona-se, deseja participar dos momentos do ciclo da vida, dentre eles o processo de gravidez, parto e puerpério [6].

"A presença do acompanhante no parto descrito como humanizado é esperada e indicada como medida que traz benefícios diretos à mulher, ao RN, a família" [7: 387].

Fortes et al. [8:40] acrescentam que "na hora do parto, a mulher escolheu seu parceiro como companheiro, inconscientemente 0 mesmo se responsabilizaria por todos os acontecimentos, pelo psicológico de sua mulher, e o desejo de tentar aliviar os medos e a dor que a mesma estava sentindo naquele momento, afinal, ele se vê ali, sendo a única fonte de apoio, ou seja, ele se vê como a única pessoa conhecida que sua mulher pode contar naquele momento".

\section{$2^{2}$ Categoria: Foi muito importante}

Apurando esta categoria, percebe-se que três informantes afirmam que foi muito importante a presença do pai no momento do parto. Elas gostaram muito de compartilharem e dividirem com ele essa ocasião:

"Foi muito importante gostei muito da ideia, sem muita burocracia. Perguntou se podia entrar, na mesma hora foi e foi muito bom, gostei muito." (P1).

"Achei muito importante porque ele pode como posso dizer, dividir né. Ele acompanhou a gravidez inteira, em todos os momentos ele estava lá presente." (P4).

"Foi muito importante pra mim [...] Saber que ele está vendo as filhas dele nascerem e que ele vai estar do lado delas o tempo todo. Foi o mais importante saber que ele desde o nascimento estava presente." (P10).

A importância de ter o companheiro no momento do parto desperta à puérpera significados jamais vivenciados em outras situações, marcando-o como único e de grande importância.

Longo et al. [7:390] expressam que "os benefícios promovidos pela presença física e/ou pelo suporte do acompanhante à parturiente, durante o processo de parturição, são descritos como consistentes pela Medicina Baseada em Evidência".

\section{3를 Categoria: Calma e tranquilidade} tranquila:

Apenas uma respondente afirma que a presença do pai deixou-a mais calma e

"Depois que ele entrou eu fiquei bem mais calma. Eu fiquei mais tranquila." (P3).

Para essa participante a presença do pai proporcionou mais tranquilidade e a acalmou, o que foi muito importante para ela, haja vista que no momento do parto a mulher fica fragilizada e tendo alguém por perto que a acalme e a tranquilize ela enfrenta as dificuldades muito melhor.

No entender de Fortes et al. [8:52] "acompanhando a mulher em todo o processo do parto o homem ajuda indiretamente dando apoio e carinho a ela e ao filho a nascer. Sem este apoio seria muito mais difícil para a mulher passar por tudo isso sozinha, o que poderia refletir no parto". 
Ao analisar as respostas das integrantes do estudo referentes à segunda questão aberta: "Como você se sentiu ao ter o pai presente no momento do parto?", emergiram-se quatro categorias: "bem, bastante emocionada e muito feliz"; "mais confiante e segura"; "estar vivendo e dividindo um momento só nosso" e "mais tranquila".

\section{$1{ }^{a}$ Categoria: Bem, bastante emocionada e muito feliz}

Ao analisar esta categoria, constata-se que cinco participantes sentiram-se bem, bastante emocionadas e muito felizes ao terem, no momento do parto, a presença de um familiar tão importante que quis participar, proporcionando o encontro de pai, mãe e filho. Ademais dá para ver a emoção do pai neste instante.

\footnotetext{
"Me senti bem, senti que tem alguém da minha família." (P1).

"Fiquei emocionada, bastante emocionada porque a gente vê a emoção 'dele' também na hora do nascimento." (P4).

"Me senti muito feliz por ele participar." (P6).

"Me senti muito bem." (P7).

"Ai, nem sei te explicar [...] assim, felicidade por estar ali os três, por ele querer estar ali junto. Felicidade." (P9).
}

O nascimento de uma criança é um acontecimento inesquecível, único e cercado de emoções para mulheres que sonhavam em ser mãe. Quando uma mulher vivencia esse acontecimento junto com o pai, sentimentos de felicidade, emoção e bem-estar se intensificam. A mulher agora mãe e o homem agora pai, deixam de ser marido e mulher e se tornam uma família completa: mãe, pai e filho.

O homem dos dias atuais tem o desejo de estar presente em todos os momentos que envolvem o nascimento do seu filho, quer tornar-se pai ao mesmo tempo em que a mulher se torna mãe. Quer ficar junto de sua companheira, participando da gestação e de todo o processo da parturição, ajudando-a a parir o filho, que enfim, é dos dois [9].

\section{$2^{2}$ Categoria: Mais confiante e segura}

Aguçando esta categoria, é possível ver através das falas de quatro puérperas o quanto a presença do pai neste momento as deixou mais confiantes e seguras, sendo até mesmo comparada com um abrigo.

"Além de confiar no médico, você tem mais confiança de ter alguém da família ali." (P1).

“[...] sentimento de segurança mesmo." (P2).

"Exatamente isso: segurança [...]." (P8).

"Uma segurança. Como se diz um abrigo. Um abrigo seguro ter ele ali. Foi muito bom ter ele ali." (P10).

O trabalho de parto e o parto podem ser cercados por sentimentos de insegurança $e$ medo quando não vivenciados anteriormente. A puérpera se sente mais segura com alguém ao seu lado durante a vivência de tal situação.

No entender de Zorzi [9], o marido não envolve preparo técnico, mas representa o suporte psíquico e emocional de que a parturiente necessita nesse momento.

Dentro das concepções de Longo et al. [7] a parturiente deposita no acompanhante a segurança de ter alguém próximo e confiável.

\section{3를 Categoria: Estar vivendo e dividindo um momento só nosso}

Apenas uma respondente relata estar vivendo e dividindo um momento único entre eles: pai e mãe. 
"Eu tive um sentimento assim de estar vivendo uma coisa nossa. De estar dividindo um momento só nosso. Outras pessoas quiseram assistir o parto, mas eu disse que não, que tinha que ser só nós dois mesmo." (P3).

O momento do parto vivenciado pelo casal não apenas fortalece o vínculo familiar entre mãe, pai e filho, mais se torna uma experiência única e enriquecedora para as pessoas envolvidas.

O que se percebe é que o envolvimento paterno intenso, quando permitido fortalecerá os vínculos futuros de assistência e afeto familiar, tanto em relação ao bebê quanto com a mãe [10].

\title{
$4^{a}$ Categoria: Mais tranquila
}

Por meio da fala de uma puérpera pode-se perceber o quanto ela se sentiu mais tranquila com a presença do pai no momento do parto.

\begin{abstract}
"Me senti mais tranquila, enquanto não entra parece que você fica meio tensa, na expectativa, porque você não sabe se vai acontecer alguma coisa, como é que vai ser, quem vai ver o que está acontecendo. Então acho que dá tranquilidade durante o momento do parto." (P5).
\end{abstract}

Em um local desconhecido e com pessoas não habituais de sua convivência, a puérpera se fragiliza, sofre tensão e insegurança pelo incerto. Quando se torna presente a companhia do pai no momento do parto a puérpera se sente mais tranquila frente à situação vivenciada, o que favorece uma vivência positiva do processo de parturição.

A efetivação da presente pesquisa permitiu visualizar o quão importante é para a mulher a presença do pai no momento do parto, haja vista que lhe proporciona segurança, força, felicidade, calma e tranquilidade. Ademais une o casal, pois estarão vivendo e dividindo um momento muito especial para ambos.

Estando o pai presente na hora do parto, a mulher ficará menos ansiosa, visto que alguém de seu convívio pessoal e fundamental na partilha desta vivência estará lhe fornecendo apoio, atenção e carinho.

Os profissionais de saúde precisam ter ciência da importância do acompanhante no processo de parturição procurando ter um bom relacionamento com ele.

Espera-se que a situação de dimensão positiva, constatada neste estudo, de benefícios proporcionados não somente a mulher como também ao pai e ao bebê, relatada pelas entrevistadas ao vivenciaram o acompanhamento do pai no momento do parto, contribua para que os profissionais da área da saúde se comprometam em buscar estratégias que melhorem a participação e comunicação com os pais, seguindo a ética profissional, respeitando o direito da gestante em ter seu parceiro acompanhando-a não apenas no momento do parto, mas durante todo o pré-natal até o pós-parto imediato, e consequentemente, promovendo uma assistência com qualidade tanto para a gestante quanto para a díade: pai e filho.

\section{Referências}

1. Brasil. Diário Oficial da União. Lei ํo11.108. Altera a Lei $n=8.080$, de 19 de setembro de 1990, para garantir às parturientes o direito à presença de acompanhante durante o trabalho de parto, parto e pós-parto imediato, no âmbito do sistema único de saúdeSUS. Brasília: Diário Oficial da União; 2005.

2. Ziegel EE, Cranley MS. Enfermagem Obstétrica. Rio de Janeiro: Guanabara Koogan; 2011.

3. Souza TG, Gaiva MAM, Modes PSS. A humanização do nascimento: percepção dos profissionais de saúde que atuam na atenção ao parto. Rev Gaúcha Enferm 2011;32(3):479-86.

4. Dodou HD, Rodrigues DP, Guerreiro EM, Guedes MVC, Lago PN, Mesquita NS. A contribuição do acompanhante para a humanização do parto e nascimento: percepções de puérperas. Esc Anna Nery 2014;18(2):262-69. 
5. Marconi MA, Lakatos EM. Técnicas de Pesquisa: planejamento e execução de pesquisas, amostragens e técnicas de pesquisas, elaboração, análise e interpretação de dados. São Paulo: Atlas; 2010.

6. Dyniewicz AM. Metodologia da pesquisa em saúde para iniciantes. 2a ed. São Caetano do Sul, São Paulo: Difusão; 2009.

7. Longo CSM, Andraus LMS, Barbosa MA. Participação do acompanhante na humanização do parto e sua relação com a equipe de saúde. Rev Eletronica Enferm 2010;12(2):386-91

8. Fortes AFA, Pinelli AB, Magalhães MAM, Almeida QP. Acompanhamento no pré, trans e pós-parto imediato: significados e sentimentos dos pais [TCC]. Itajubá: Escola de Enfermagem Wenceslau Braz; 2013. 88p.

9. Espirito Santo LC, Bonilha ALL. Expectativas, sentimentos e vivências do pai durante 0 parto e nascimento de seu filho. Rev Gaucha Enf 2000;21(2):87-109.

10. Zorzi NT. Reflexão sobre a participação do pai no momento do nascimento. [citado 2015 Maio 12]. Disponível em URL:

http://www.amigasdopartoprofissionais.com/2011/05/reflexao-sobreparticipacao-do-pai.html. 